\title{
Ligneous Conjunctivitis Treated with Systemic Plasminogen - A Rare Case Report
}

\author{
Utkarsha Ramakant Deshmukh ${ }^{1}$, Saheb Lal Adile ${ }^{2}$ \\ ${ }^{1}$ Department of Ophthalmology, LSLAMGMC, Raigarh, Chhattisgarh, India. \\ ${ }^{2}$ Department of Ophthalmology, LSLAMGMC, Raigarh, Chhattisgarh, India.
}

\section{INTRODUCTION}

Ligneous conjunctivitis (LC) is a rare condition characterized by chronic, recurrent conjunctivitis associated with the development of pseudo-membranes on the palpebral surfaces which produce thick nodular masses that replace the normal mucosa. ${ }^{[1]}$ Although ophthalmic involvement is the most common manifestation of the disease, the less frequent involvement of other mucosal membranes such as larynx, vocal cords, gingiva, trachea, nasopharynx, tympanic membranes, vagina and cervix has been reported. ${ }^{[2]}$ Ligneous conjunctivitis may be inherited in an autosomal recessive pattern due to mutations in the plasminogen (PLG) gene and a variety of other genes; it is associated with type I PLG deficiency (hypoplasminogenemia).[3] Simple excision of the woody membranes leads to recurrence; so, different methods are recommended in several case reports in the literature. ${ }^{[4]}$ Simple excision of the woody membranes leads to recurrence, so different methods are recommended in several case reports in the literature. Here we report a case of 13-year-old boy with ligneous conjunctivitis who was successfully treated with systemic administration of plasminogen factor which has led to excellent symptomatic relief in the patient.

\section{PRESENTATION OF CASE}

A 13-year-old boy reported to the ophthalmology OPD with history of recurrent episodes of swelling and redness in both eyes along with defective vision since 2 years of age in both the eyes. There was history of hospitalization for the same complaints multiple times in the past elsewhere, without success. The patient presented to us with BCVA of PL +ve in both eyes. On examination, there was bilateral conjunctival hyperaemia and pseudomembranes having sticky discharge with a woody-like consistency in upper and lower tarsal conjunctiva. The pseudomembranes were more prominent and profuse in the left eye than the right eye, with chemosis. The left eye also revealed corneal ulceration with neovascularisation in the central and paracentral area, and the right eye had peripheral corneal abrasions. [Fig. 1, 2]

The patient was admitted in ophthalmology ward and started with topical cyclosporine $(0.3 \%)$ TDS, topical reconstituted heparin $(0.4 \%)$ and topical fresh frozen plasma (FFP) (in sterile drop bottles, at 4 degree C) 1 hourly, topical moxifloxacin 6 times a day for both eyes and topical cyclopentolate (1\%, BD) for the left eye.
Corresponding Author: Dr. Utkarsha Ramakant Deshmukh, C/o. Mukund Dehankar, Behind Shri Ram Mandir, Tilak Nagar, Bilaspur-495001, Chhattisgarh, India.

E-mail: drutkarsha1987@gmail.com

DOI: $10.14260 /$ jemds/2020/70

Financial or Other Competing Interests: None.

How to Cite This Article: Deshmukh UR, Adile SL. Ligneous conjunctivitis treated with systemic plasminogen- a rare case report. J. Evolution Med. Dent. Sci. 2020;9(05):309311, DOI: 10.14260/jemds/2020/70

Submission 29-11-2019,

Peer Review 10-01-2020

Acceptance 16-01-2020,

Published 03-02-2020. 

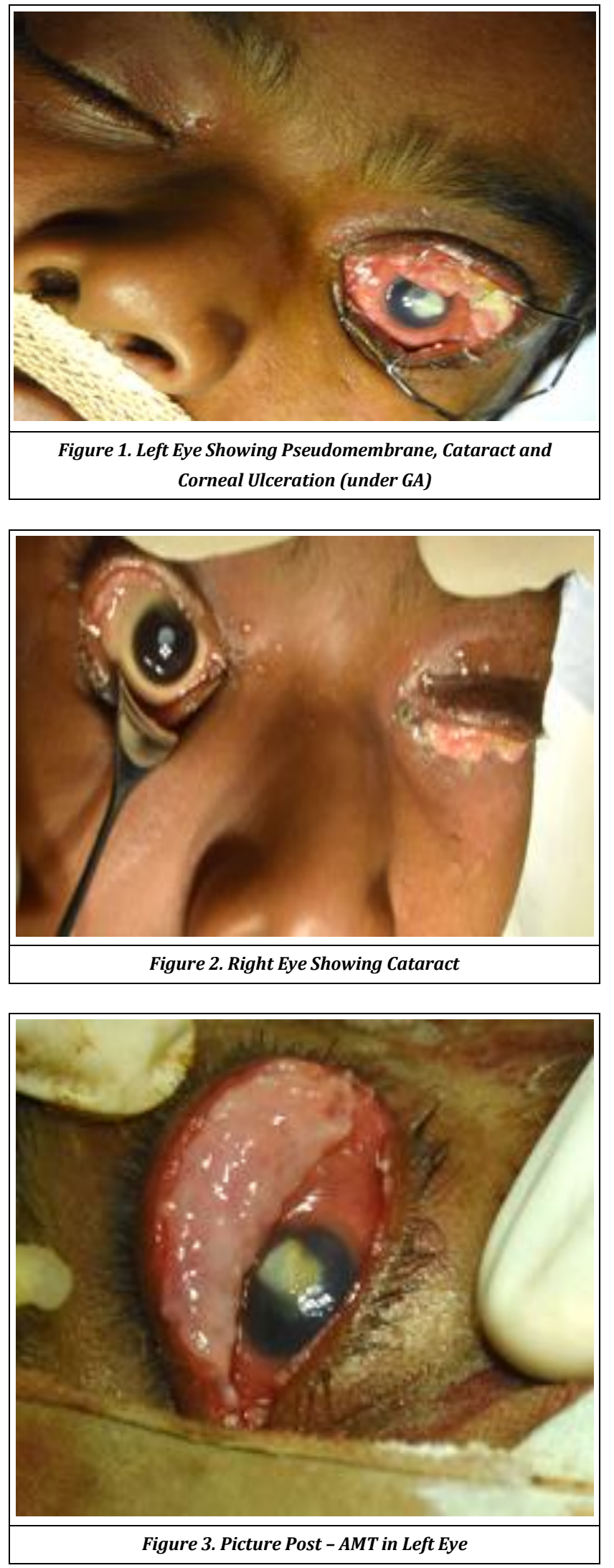

Later on, as the patient was not responding to topical therapy, he underwent LE- pseudomembrane excision with sutureless amniotic membrane transfer (AMT) (freshly extracted, procured from gynaecology dept.) over upper tarsal conjunctiva under GA. [Fig. 3] The excised material was sent for histopathological examination. The histopathological examination reported multiple serial sections showing stratified squamous epithelium, with focal areas of inflammation. Sub epithelial layer showed infiltration by mixed inflammatory cells, the features were suggestive of chronic, nonspecific inflammatory lesion. [Fig. 4]

There was some response to this intervention, but the improvement was sluggish. So, we decided to administer intravenous FFP to correct the systemic plasminogen deficiency. Thereafter, in consultation with the paediatrician and haematologist, and following the routine protocol mandatory before doing blood transfusion, we calculated the dose of systemic intravenous FFP to be administered (194 ml) to deliver systemic plasminogen. After this systemic infusion of FFP, we were happy to note that the patient showed dramatic improvement in signs and symptoms, he started opening the eyes properly and co-operating in examination and vision testing. The patient was then advised to undergo RE SICS with PCIOL implantation to prevent amblyopia. On follow up examination up to 8 weeks, the patient felt symptomatically relieved, there was no recurrence of pseudomembranes in either eye. The right eye BCVA was 6/36.

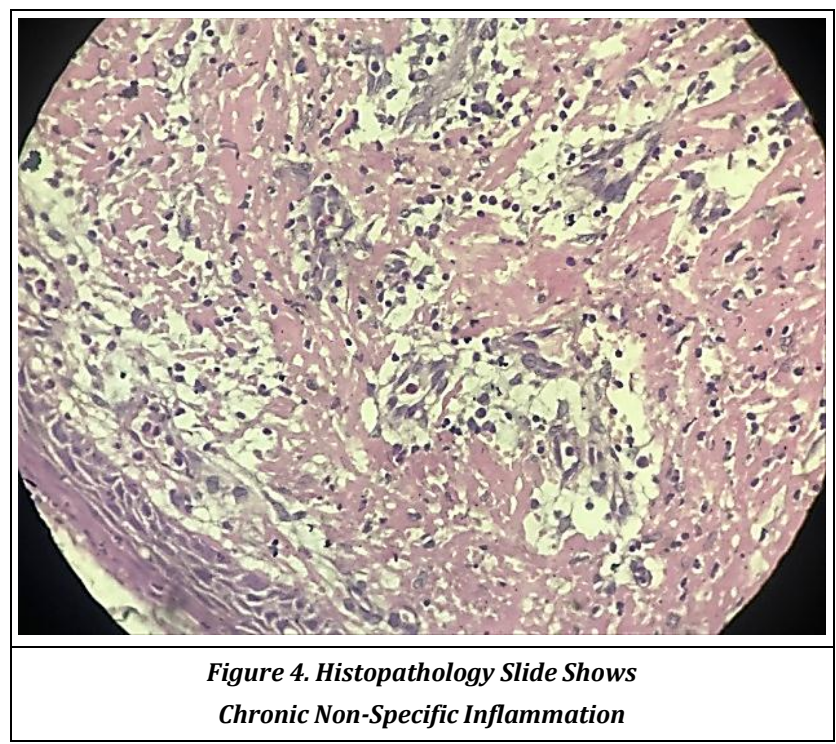

\section{DISCUSSION}

Ligneous conjunctivitis was first reported in a 46-year-old man with bilateral pseudomembranous conjunctivitis as early as 1847.[5] Verhoeff coined the term "recurrent pseudomembranous granuloma of the palpebral conjunctiva"[6] while Mingers., et al. proposed the term "pseudomembranous disease" to describe systemic character of this clinical entity.[7] In 2001, Lecame., et al. estimated a total of 119 reported cases of ligneous conjunctivitis in last 50 years. ${ }^{[8]}$ In patients with LC, there is a major deficiency of plasmin-mediated extracellular fibrinolysis that is required in the normal process of wound healing and is required for initial removal of the fibrin-rich matrix as well as for the remodelling of the granulation tissue and completion of wound healing as well as the capacity of cellular migration. ${ }^{[9]}$ Systemic lys-plasminogen application has found to restore wound-healing capacity and resolve ligneous lesions.[9] 


\section{CONCLUSIONS}

There have been several instances reported in literature of ligneous conjunctivitis being successfully treated with topical therapy and AMT. Here we report a first of its kind case in India in which the systemic administration of plasminogen factor has led to excellent symptomatic relief in the patient.

\section{REFERENCES}

[1] McCullough K, Nguyen H, Stechschulte D, et al. Ligneous conjunctivitis: a case report with multiorgan involvement. Histopathology 2007;50(4):511-3.

[2] Schuster V, Seidenspinner S, Müller C, et al. Prenatal diagnosis in a family with severe type I plasminogen deficiency, ligneous conjunctivitis and congenital hydrocephalus. Prenat Diagn 1999;19(5):483-7.

[3] Mehta R, Shapiro AD. Plasminogen deficiency. Haemophilia 2008;14(6):1261-8.
[4] Azad N, Zafar S, Khan A. Successful treatment of ligneous conjunctivitis with topical cyclosporine and heparin. J AAPOS 2009;13(5):519-20.

[5] Bouisson M. Ophthalmie sur-aigue avec formation de pseudomembranes a la surface de la conjonctive. Annals of Oculist 1847;17:100-104.

[6] Verhoeff FH. A case of ligneous conjunctivitis now 36 years in duration. American Journal of Ophthalmology 1958;45(4 Pt 2):246-51.

[7] Mingers AM, Heimburger N, Zeitler P, et al. Homozygous type I plasminogen deficiency. Seminars in Thrombosis and Hemostasis 1997;23(3):259-69.

[8] Lecame M, Conan S, Le Jeune V, et al. Treating a ligneous conjunctivitis with false membrane through a local tritherapy: a glucocorticoid, an anticoagulant and an immunosuppressor. Journal de Pharmacie Clinique 2001;20(1):25-7.

[9] Hidayat AA, Riddle PJ. Ligneous conjunctivitis. A clinicopathologic study of 17 cases. Ophthalmology 1987;94(8):949-59. 